\title{
APPLYING A KANO QUALITY MODEL FOR INTELLIGENT GREEN BUILDING DESIGN STRATEGIES IN TAIWAN
}

\author{
Yi-Kai JUAN ${ }^{\text {a, *, Sheng-Jhao Hsu HUANG }{ }^{\text {a }} \text {, Hung-Ting CHEN }}{ }^{\text {a }}$ \\ ${ }^{a}$ Department of Architecture, National Taiwan University of Science and Technology (NTUST), \\ 43, Section 4, Keelung Road, Taipei, Taiwan
}

Received 15 August 2012; accepted 28 February 2013

\begin{abstract}
Intelligent green building (IGB) industry has received considerable global recognition due to the rapid development of advanced technology, intelligent materials, innovative products, and services in recent years. Although various cross-domain experiments and practices with respect to IGB projects are ready for operation, the notion and benefits of IGB are still ambiguous and debatable. The purpose of this study is to apply a Kano quality model and a customer satisfaction matrix to evaluate professional designers' and general users' satisfaction, preferences, and acceptability of IGB design strategies. The study result reveals that the proposed approach could be a useful tool to explore similarities and discrepancies of strategy preferences between designers and users, and these findings could effectively decrease the communication gap for future IGB design.
\end{abstract}

KEYWORDS: Intelligent green building; Design strategies; Kano two-dimensional quality model; Customer satisfaction matrix; Taiwan

REFERENCE to this paper should be made as follows: Juan, Y.-K.; Huang, S.-J. H.; Chen, H.-T. 2014. Applying a Kano quality model for intelligent green building design strategies in Taiwan, International Journal of Strategic Property Management 18(2): 125-137.

\section{INTRODUCTION}

Energy consumption by buildings generally accounts for $30-40 \%$ of the total energy consumption in advanced countries (Pérez-Lombard et al. 2008). Many global organizations have been considering a series of effective policies to create more sustainable built environments (Mickaityte et al. 2008). During the past decade, advances in information, communication, and technology (ICT) have prompted a revolution in the building industry (Xue et al. 2012). One of the most significant breakthroughs is the emergence of the so-called "intelligent green buildings" (IGBs), in which an application of ICT, intelligent materials, and innovative products and services can simultaneously increase intelligence and sustainability of buildings (Skibniewski 2008). Considering the potential of embodying ICT components in green buildings, a few multidisciplinary experiments and practices have been deployed to

\footnotetext{
* Corresponding author. E-mail: rik@mail.ntust.edu.tw
}

evaluate the feasibility of these IGB projects (Adeli 2008; Yang et al. 2012; Raju, Ahmed 2012).

Taiwan, with a population of only 23 million, has been regarded as a "Technology Island" carving out a huge niche in the global ICT industry. Approximately $67 \%$ of the national $R \& D$ expenditure can be attributed to the ICT industry (Chen 2002). In addition, the Taiwan government is also one of the relatively few governments that have launched the green building certification system before 2000 . With more than 10 years of implementing experience, the government has developed a comprehensive system to evaluate performance of green buildings. In 2010, the government further proposed the "Intelligent Green Building Promoting Scheme", which promises that more than US $\$ 100$ million dollars would be invested in supporting ICT applications for green buildings and enhancing industrial competitiveness in the following six years (Executive Yuan 2010).

Since the concept of IGB is still a relatively new and interdisciplinary field in the building industry, 
limited studies have been attempted to explore its benefits, market demands, and user acceptability toward IGB projects, meaning that the assessment for ICT-green technologies and strategies, namely IGB design strategies, is full of ambiguity and paradoxes (Chau et al. 2010). Considering the customer's requirements and marketability of technology, three distinct research questions gradually come to mind. Are customers aware of the potentials of IGB design strategies? Are customers satisfied with these promising strategies? Is there any conscious gap between designers and users when adopting these strategies?

The objective of this research is to apply a Kano two-dimensional quality model to classify feasible IGB design strategies into five categories, namely "Attractive", "One-dimensional", "Must-be", "Indifferent", and "Reverse", based on customers' preferences (Kano et al. 1984). By adopting the customer satisfaction coefficient developed by Matzler and Hinterhuber (1998), these strategies can be further quantified to establish a customer satisfaction matrix for evaluating satisfied and unsatisfied preferences. Two groups comprising thirty professional designers and thirty general users were invited to test the proposed IGB design strategies. Preference similarities and discrepancies between the two groups and potentials of the application of these strategies were also discussed.

\section{INTELLIGENT GREEN BUILDING (IGB)}

Green Building (GB) is a design that focuses on increasing the efficiency of use of resources, energy, water, and materials while reducing building and environment impacts during a building's life cycle (Tam et al. 2012). To mitigate and measure these impacts, many GB rating systems, such as LEED, BREEAM, and GBTools, have been developed (USGBC 1999; BRE Global 2008; GBC Green Building Tool 2005). The Taiwanese government established the "Green Building Evaluation and Labeling System" in 1999 to promote the concept of green buildings. This system includes nine indicators: biodiversity, greenery, soil water content, daily energy saving, $\mathrm{CO}_{2}$ emission reduction, waste reduction, indoor environment, water resource, and sewage and garbage improvement (ABRI 2003).

The term of "Intelligent Building" (IB) was first used in the United States in the early 1980s, and its original definition is a building that can integrate various systems to effectively manage resources in a coordinated way to maximize technical and operating performance (Clements-Croome 1997). As automatic and interactive technologies between users and environments develop, different understanding and inconsistent interpretation of building intelligence indeed exist (Wong et al. 2005). For instance, the U.S. system focuses more on technology, while the UK system pays more attention to user's requirements (Wigginton, Harris 2002). In Taiwan, the government also officially enacted the "Intelligent Building Evaluation and Labeling System" in 2003, presenting eight indicators, including intelligent wiring system, ICT application, integrated building system, intelligent facilities management, safety and security system, user comfort, intelligent convenience, and energy management system, which both take inspiration from the US and UK systems of technology and user issues (ABRI 2011).

Some studies have indicated that integrating technology systems of buildings and constructing sustainable (or green) buildings have much in common; IBs make GBs greener, and GBs make IBs smarter (Sinopoli 2008). That is, IBs and GBs are not on opposite sides, and, in fact, IGB practices offer an opportunity to create environment-friendly and resource-efficient buildings through using an integrated approach to design and operate (Boyle 2005). Based on extensive experiences of implementation with respect to GB and IB, as well as promising ICT applications, the Taiwan government has been aware that integration of the ICT industry advantage of Taiwan with the concept of energy saving and carbon reduction to create an interdisciplinary practice of IGB will become one of the major policies for continually promoting the development of national technology industry. The term "IGB" here is widely defined as adoptions of ICT, intelligent materials, and innovative products and services on green buildings to make buildings safer, healthier, more convenient, and more energy saving. It is a dual-track implementation with both GB and IB certifications (Ho 2011). At the end of 2010, the government approved the "Intelligent Green Building Promotion Program", and it is expected that in the next six years, more than US $\$ 100$ million dollars from the public fund will be invested in promoting IGB-related industries, bringing more than US $\$ 250$ billion of industry values and creating over 240,000 job opportunities (Executive Yuan 2010).

\section{IGB DESIGN STRATEGIES}

GB is about resource efficiency, life-cycle effects, and building performance. IB, whose core value is integrated building technology systems, is about 
construction and operation efficiencies (Sinopoli 2008). The concept of IGB is basically an integration of IB and GB. Unlike numerous studies regarding design strategies of IB and GB that many researchers, academics, and professionals have been involved in, there has been a very limited amount of research into the IGB. Table 1 summarizes the interaction between existing criteria of IB and GB systems in Taiwan as evaluated by the panel of experts including twelve professionals from academia and industries. As an exploratory study, the matrix provides a basic platform for all participants involved in developing a new assessment system and relative criteria for IGB.

Although the assessment system for IGB is still under development, the matrix illustrates the priority of developing feasible design strategies or technologies for IGB. For example, the intersection of "Waste Reduction" and "Intelligent Facilities Management," representing a strong relationship, implies that applying the RFID technology to check green material adoptions and reduce material waste in the building could be a potential strategy. To validate the matrix and recognize potential IGB design strategies, seven green and intelligent building projects completed in 2010 at Taipei and New Taipei City are reviewed (see Appendix A). From the case study of investigating these projects, twenty-seven design strategies are collected as shown in Fig. 1.

\section{METHODOLOGY}

\subsection{Kano two-dimensional quality model}

The Kano two-dimensional quality model is a useful tool to classify and prioritize customer needs. It can also address the nonlinear relationship between performance-related quality attributes of a product (or service) and overall customer satisfaction (Kano et al. 1984). These quality attributes, as shown in Fig. 2, can be classified into five categories: (1) must-be attributes are expected by the customers and will result in dissatisfaction when these attributes are not fulfilled; (2) onedimensional attributes are those for which better

Table 1. IB-GB criteria matrix (ABRI 2003; ABRI 2011)

\begin{tabular}{|c|c|c|c|c|c|c|c|c|}
\hline IB criteria & 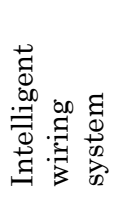 & 卢 & 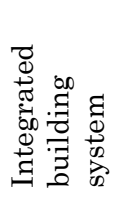 & 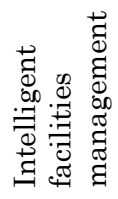 & 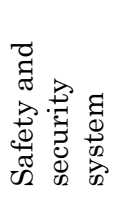 & 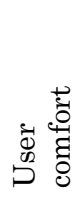 & 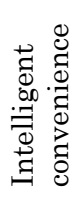 & 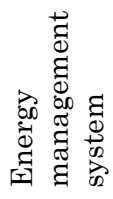 \\
\hline A. Biodiversity & & $\Delta$ & & & & O & & \\
\hline B. Greenery & & $\Delta$ & & & O & (a) & & $\circ$ \\
\hline C. Soil water content & & $\Delta$ & & & (2) & ० & & $\Delta$ \\
\hline D. Daily energy saving & $\Delta$ & ○ & (a) & ० & & (2) & & (2) \\
\hline E. $\mathrm{CO} 2$ emission reduction & $\Delta$ & (a) & $\circ$ & (a) & & ० & & (2) \\
\hline F. Waste reduction & 0 & (a) & $\Delta$ & (a) & & $\Delta$ & ○ & \\
\hline G. Indoor environment & (2) & (2) & (2) & ○ & (a) & (a) & $\Delta$ & ० \\
\hline H. Water resource & ० & (a) & (a) & $\Delta$ & $\Delta$ & & & $\Delta$ \\
\hline I. Sewage and garbage improvement & & 0 & & ० & $\Delta$ & $\Delta$ & o & \\
\hline
\end{tabular}

Note: “○”, “○”, and “ $\Delta$ ” mean strong, moderate, and weak relationships between GB and IB criteria, respectively.

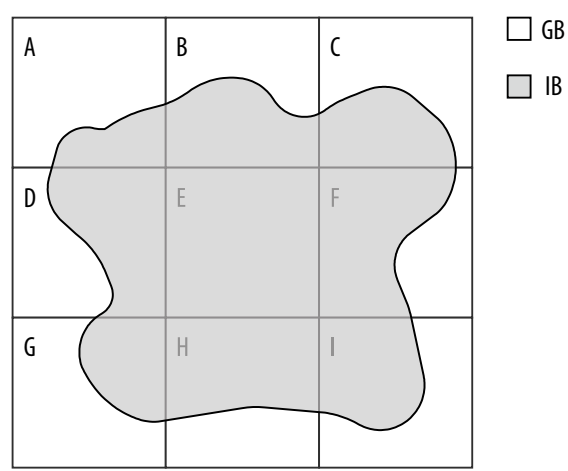

B1 Intelligent vegetal wall system
B2 Intelligent roof greening system
C1 ICT-based permeable pavement
C2 Rainwater infiltration technologies
D1 Intelligent energy monitoring system
D2 Inductive shutter
D3 Solar photoelectric glass
D4 Nano-coating solar panels
D5 Inductive ventilating tower
D6 Earth cooling tube system
D7 Intelligent VRV system
D8 Intelligent heat exchanger system
D9 Intelligent cold storage system
D10 Solar-tracking light-guide plates

B1 Intelligent vegetal wall system B2 Intelligent roof greening system 1 ICT-based permeable pavement C2 Rainwater infiltration technologies D2 Inductive shutter D3 Solar photoelectric glass D4 Nano-coating solar panels D5 Inductive ventilating tower D6 Earth cooling tube system 7 Intelligent VRV system D9 Intelligent cold storage system D10 Solar-tracking light-guide plates

\author{
D11 Smart roof light-guide system \\ E1 Intelligent CO2 monitoring system \\ F1 BIM-based management system \\ F2 RFID-based material checking \\ G1 IEQ monitoring system \\ G2 Automatic humidity controlling system \\ G3 Adaptive lighting system \\ G4 Intelligent fire alert system \\ G5 Intelligent fire compartment system \\ G6 Build damage monitoring system \\ $\mathrm{H} 1$ Intelligent graywater recycling system \\ $\mathrm{H} 2$ Inductive rainwater recycling system \\ H3 Inductive water-saving equipment
}

Fig. 1. Design strategies of IGB 
fulfillment leads to linear increment of customer satisfaction; (3) attractive attributes are usually unexpected by the customers and can result in great satisfaction if they are available; (4) indifferent attributes are those that the customers are not interested in the level of their performance; and (5) reverse attributes refer to a high degree of achievement resulting in dissatisfaction (Kano et al. 1984; Berger et al. 1993; Matzler, Hinterhuber 1998; Xu et al. 2009).

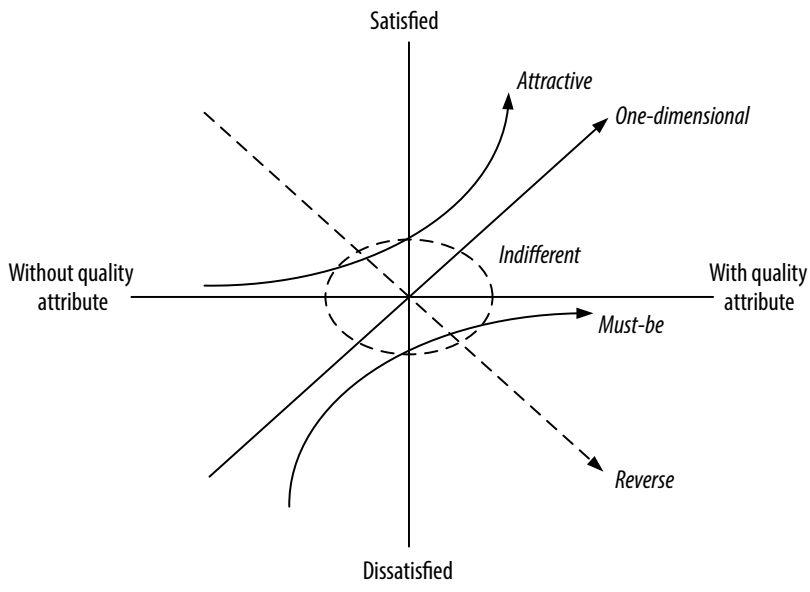

Fig. 2. Kano two-dimensional quality model

The Kano model has been widely used in various research fields, such as bank services (Bhattacharyya, Rahman 2004), e-services (Fundin, Nilsson 2003), travel services (Shahin 2004). Most of these studies have focused on discussing the relationship between quality attributes and customer satisfaction, especially on how this model can be applied in new empirical contexts for product (or service) development (Löfgren, Witell 2008). Majority of these research themes are the classifications of different quality attributes to recognize customer needs (Löfgren, Witell 2008). Therefore, by adopting the Kano model, customer needs in this research, such as preferences for IGB design strategies, can be effectively classified and indentified.

\subsection{Research process: a three-stage quantitative assessment for IGB design strategies}

Although there are many advantages of adopting the Kano model in identifying the relationship between quality attributes and customer satisfaction, the nature of qualitative assessment of the Kano model usually causes some limitations, which could not precisely reflect the extent to which the customers are satisfied (Wassenaar et al. 2005). That is, the traditional Kano method cannot be equipped with quantitative assessment (Xu et al. 2009). Therefore, a three-stage quantitative assessment process based on improving the Kano model is further developed (Berger et al. 1993; Matzler, Hinterhuber 1998).

First, a questionnaire that consists of positive/ functional and negative/dysfunctional is established. The customer can answer a pair of questions in one of five different ways, "Like", "Mustbe", "Neural", "Live with" and "Dislike", for each attribute of a product (or service). The first question concerns the reaction of the customer if the product (or service) has that attribute (functional form); the second involves the reaction if the product (or service) does not have that attribute (dysfunctional form) (Matzler, Hinterhuber 1998).

Second, the questionnaire is administered to various customers, and each answer pair is aligned with the Kano evaluation table (Berger et al. 1993), as shown in Table 2, which can reveal each customer's perception toward attributes of a product (or service) (Xu et al. 2009; Lin et al. 2010). If the customer answers, for example, "I like it that way" as regards a specific attribute from the functional side, and answers "I am neural" for the same attribute from the dysfunctional side, the combination of the question in the evaluation table will be in the " $\mathrm{A}$ " category, indicating that this attribute is attractive to customer needs.

Third, the use of the customer satisfaction coefficient (CSC), as show in equations (1) and (2), is applied to understand how strongly a product (or service) attribute may affect satisfaction or, in the case of its nonfulfillment, customer dissatisfaction. The positive CSC ranges from 0 to 1 . The closer the value is to 1 , the higher the influence on customer satisfaction. On the contrary, if the negative CSC approaches -1 , the influence on customer dissatisfaction is especially strong if the attribute of the product (or service) is not fulfilled. A value of

Table 2. Kano evaluation table (Berger et al. 1993)

\begin{tabular}{|c|c|c|c|c|c|c|}
\hline & \multicolumn{5}{|c|}{ Dysfunctional } \\
\hline & & Like & Must-be & Neural & Live with & Dislike \\
\hline \multirow{5}{*}{ 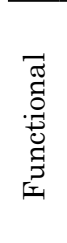 } & Like & $\mathrm{Q}$ & A & $\mathrm{A}$ & A & $\mathrm{O}$ \\
\hline & Must-be & $\mathrm{R}$ & I & I & I & M \\
\hline & Neural & $\mathrm{R}$ & I & I & I & M \\
\hline & Live with & $\mathrm{R}$ & I & I & I & M \\
\hline & Dislike & $\mathrm{R}$ & $\mathrm{R}$ & $\mathrm{R}$ & $\mathrm{R}$ & $\mathrm{Q}$ \\
\hline
\end{tabular}

Note: Q, A, R, I, O, and M denote "Questionable", "Attractive", "Reverse", "Indifferent", "One-dimensional" and "Must-be" attributes, respectively. 
0 implies that this attribute has a low influence, which does not cause dissatisfaction if it is not fulfilled (Matzler, Hinterhuber 1998).

Extent of satisfaction coefficient

$(\mathrm{SC})=(\mathrm{A}+\mathrm{O}) /(\mathrm{A}+\mathrm{O}+\mathrm{M}+\mathrm{I})$,

Extent of dissatisfaction coefficient

$(\mathrm{DSC})=-(\mathrm{O}+\mathrm{M}) /(\mathrm{A}+\mathrm{O}+\mathrm{M}+\mathrm{I})$.

\section{KANO TWO-DIMENSIONAL QUALITY MODEL FOR IGB DESIGN STRATEGIES}

\subsection{Experimental groups}

To understand the preferences of different customers for IGB design strategies, two groups comprising thirty professional designers and thirty general users were invited to test these strategies (see Appendix B). The designers group consists of principal architects, project managers, design directors, and senior architectural designers from different companies. The users group comprises the directors of community committee and facility managers of various office buildings. Among these respondents, four (6.7\%) had never heard of the concept of IGB and therefore data analysis from these respondents was excluded. Twelve general users and four professional designers had a very limited knowledge of IGB strategies. More explanations and illustrations regarding benefits, features, and applications of these strategies were introduced in advance before the questionnaire was answered.

\subsection{Data analysis}

The questionnaire was first tested for internal consistency based on the notion of the Cronbach's $\alpha$ reliability coefficient. The results show that the average coefficient for the group of professional designers and general users are 0.812 and 0.724 , respectively, above the benchmark of 0.7 suggested by Nunnally (1978), interpreting that the proposed questionnaire has a high reliability suitable for data analysis. The quality attribute for each IGB design strategy and its corresponding SC/DSC for these two groups are separately illustrated in Tables 3 and 4 .

\section{RESULTS}

According to the results shown in Tables 3 and 4 , several findings with respect to the customer's preferences and satisfaction for IGB design strategies are worth further discussion.

\subsection{Same opinions on quality attributes for professional designers and general users}

As shown in Table 5, for some IGB design strategies related to human safety issues, such as "G4 Intelligent fire alert system", "G5 Intelligent fire compartment system", and "G6 Build damage monitoring system", there is no doubt that these two groups have the same opinion and regard the requirements of these strategies as "Must-be" attributes, revealing that customers will be extremely dissatisfied if these basic requirements are not fulfilled.

Strategies focusing on applying ICT to external environments and components of buildings, such as "B1 Intelligent vegetal wall system", "D2 Inductive shutter", "D3 Solar photoelectric glass", "D10 Solar-tracking light-guide plates", "D11 Smart roof light-guide system", and "H1 Intelligent graywater recycling system", are classified as "Attractive" attributes. The finding reveals that these strategies are more explicit, and fulfilling these requirements leads to more than proportional satisfaction. If they are not met, however, there is no feeling of dissatisfaction. The reason might be that customers have an intimate knowledge of these explicit strategies. Without adopting these strategies, customers can still find other alternative solutions to fulfill their requirements.

These two groups also have the same opinion on several strategies such as "C2 Rainwater infiltration technology", "D4 Nano-coating solar panels", "D9 Intelligent cold storage system", "E1 Intelligent $\mathrm{CO}_{2}$ monitoring system", "F1 BIM-based management system", and "F2 RFID-based material checking". They express their indifference toward these strategies, leading to "Indifferent" attributes. The reason might be that the benefits and advantages of these strategies are not easily perceived by customers, and therefore they do not result in either customer satisfaction or dissatisfaction.

\subsection{Discrepant opinions on quality attributes by professional designers and general users}

On the basis of Table 5, there is an interesting finding that these two groups also show discrepant opinions on some IGB design strategies related to energy-saving issues, such as "D1 Intelligent energy monitoring system", "D5 Inductive ventilating tower", "D6 Earth cooling tube system", "D7 Intelligent VRV system", and "D8 Intelligent heat exchanger system". Professional designers generally regard requirements of these strategies as "Must-be" or "Attractive" attributes, while general users take these strategies for indifference. 
Table 3. Quality attribute and satisfaction coefficient of professional designers

\begin{tabular}{|c|c|c|c|c|c|c|c|}
\hline IGB design strategies & $\mathrm{A}$ & $\mathrm{O}$ & M & I & $\begin{array}{l}\text { Quality } \\
\text { attribute }\end{array}$ & $\mathrm{SC}$ & DSC \\
\hline \multirow[t]{2}{*}{ B1 Intell. vegetal wall sys. } & 15 & 2 & 2 & 8 & $\mathrm{~A}$ & 0.63 & -0.15 \\
\hline & $54 \%$ & $7 \%$ & $7 \%$ & $29 \%$ & & & \\
\hline \multirow[t]{2}{*}{ B2 Intell. roof greening sys. } & 16 & 4 & 4 & 4 & $\mathrm{~A}$ & 0.71 & -0.29 \\
\hline & $57 \%$ & $14 \%$ & $14 \%$ & $14 \%$ & & & \\
\hline \multirow[t]{2}{*}{ C1 ICT-based permeable pavement } & 13 & 2 & 3 & 9 & $\mathrm{~A}$ & 0.56 & -0.19 \\
\hline & $48 \%$ & $7 \%$ & $11 \%$ & $33 \%$ & & & \\
\hline \multirow[t]{2}{*}{ C2 Rainwater infiltration tech. } & 7 & 2 & 7 & 12 & $\mathrm{I}$ & 0.32 & -0.32 \\
\hline & $25 \%$ & $7 \%$ & $25 \%$ & $43 \%$ & & & \\
\hline \multirow[t]{2}{*}{ D1 Intell. energy monitoring sys. } & 8 & 6 & 10 & 4 & M & 0.50 & -0.57 \\
\hline & $29 \%$ & $21 \%$ & $36 \%$ & $14 \%$ & & & \\
\hline \multirow[t]{2}{*}{ D2 Inductive shutter } & 14 & 2 & 2 & 10 & $\mathrm{~A}$ & 0.57 & -0.14 \\
\hline & $50 \%$ & $7 \%$ & $7 \%$ & $36 \%$ & & & \\
\hline \multirow[t]{2}{*}{ D3 Solar photoelectric glass } & 16 & 3 & 0 & 8 & $\mathrm{~A}$ & 0.70 & -0.11 \\
\hline & $59 \%$ & $11 \%$ & $0 \%$ & $30 \%$ & & & \\
\hline \multirow{2}{*}{ D4 Nano-coating solar panels } & 12 & 1 & 1 & 14 & I & 0.46 & -0.07 \\
\hline & $43 \%$ & $4 \%$ & $4 \%$ & $50 \%$ & & & \\
\hline \multirow[t]{2}{*}{ D5 Inductive ventilating tower } & 13 & 3 & 2 & 10 & $\mathrm{~A}$ & 0.57 & -0.18 \\
\hline & $46 \%$ & $11 \%$ & $7 \%$ & $36 \%$ & & & \\
\hline \multirow[t]{2}{*}{ D6 Earth cooling tube sys. } & 15 & 2 & 3 & 7 & $\mathrm{~A}$ & 0.63 & -0.19 \\
\hline & $56 \%$ & $7 \%$ & $11 \%$ & $26 \%$ & & & \\
\hline \multirow[t]{2}{*}{ D7 Intell. VRV sys. } & 8 & 5 & 11 & 1 & M & 0.52 & -0.64 \\
\hline & $32 \%$ & $20 \%$ & $44 \%$ & $4 \%$ & & & \\
\hline \multirow[t]{2}{*}{ D8 Intell. heat exchanger sys. } & 9 & 4 & 11 & 2 & M & 0.50 & -0.58 \\
\hline & $35 \%$ & $15 \%$ & $42 \%$ & $8 \%$ & & & \\
\hline \multirow[t]{2}{*}{ D9 Intell. cold storage sys. } & 8 & 3 & 2 & 15 & $\mathrm{I}$ & 0.39 & -0.18 \\
\hline & $29 \%$ & $11 \%$ & $7 \%$ & $54 \%$ & & & \\
\hline \multirow[t]{2}{*}{ D10 Solar-tracking light-guide plates } & 13 & 2 & 3 & 9 & $\mathrm{~A}$ & 0.56 & -0.19 \\
\hline & $48 \%$ & $7 \%$ & $11 \%$ & $33 \%$ & & & \\
\hline \multirow[t]{2}{*}{ D11 Smart roof light-guide sys. } & 13 & 3 & 1 & 8 & $\mathrm{~A}$ & 0.64 & -0.16 \\
\hline & $52 \%$ & $12 \%$ & $4 \%$ & $32 \%$ & & & \\
\hline \multirow[t]{2}{*}{ E1 Intell. CO2 monitoring sys. } & 6 & 2 & 4 & 13 & I & 0.32 & -0.24 \\
\hline & $24 \%$ & $8 \%$ & $16 \%$ & $52 \%$ & & & \\
\hline \multirow[t]{2}{*}{ F1 BIM-based management sys. } & 9 & 1 & 3 & 15 & I & 0.36 & -0.14 \\
\hline & $32 \%$ & $4 \%$ & $11 \%$ & $54 \%$ & & & \\
\hline F2 RFID-based material checking & 8 & 3 & 7 & 10 & $\mathrm{I}$ & 0.39 & -0.36 \\
\hline & $29 \%$ & $11 \%$ & $25 \%$ & $36 \%$ & & & \\
\hline G1 IEQ monitoring sys. & 11 & 4 & 0 & 10 & $\mathrm{~A}$ & 0.60 & -0.16 \\
\hline & $44 \%$ & $16 \%$ & $0 \%$ & $40 \%$ & & & \\
\hline G2 Auto. humidity controlling sys. & 9 & 4 & 2 & 11 & I & 0.50 & -0.23 \\
\hline & $35 \%$ & $15 \%$ & $8 \%$ & $42 \%$ & & & \\
\hline G3 Adaptive lighting sys. & 6 & 7 & 4 & 9 & $\mathrm{I}$ & 0.50 & -0.42 \\
\hline & $23 \%$ & $27 \%$ & $15 \%$ & $35 \%$ & & & \\
\hline G4 Intell. fire alert sys. & 3 & 3 & 12 & 10 & M & 0.21 & -0.54 \\
\hline & $11 \%$ & $11 \%$ & $43 \%$ & $36 \%$ & & & \\
\hline G5 Intell. fire compartment sys. & 4 & 5 & 11 & 8 & M & 0.32 & -0.57 \\
\hline & $14 \%$ & $18 \%$ & $39 \%$ & $29 \%$ & & & \\
\hline G6 Build damage monitoring sys. & 11 & 1 & 13 & 3 & M & 0.43 & -0.50 \\
\hline & $39 \%$ & $4 \%$ & $46 \%$ & $11 \%$ & & & \\
\hline H1 Intell. graywater recycling sys. & 14 & 2 & 0 & 12 & $\mathrm{~A}$ & 0.57 & -0.07 \\
\hline & $50 \%$ & $7 \%$ & $0 \%$ & $43 \%$ & & & \\
\hline H2 Inductive rainwater recycling sys. & 9 & 3 & 4 & 12 & I & 0.43 & -0.25 \\
\hline & $32 \%$ & $11 \%$ & $14 \%$ & $43 \%$ & & & \\
\hline H3 Inductive water-saving equip. & 7 & 6 & 1 & 14 & I & 0.46 & -0.25 \\
\hline & $25 \%$ & $21 \%$ & $4 \%$ & $50 \%$ & & & \\
\hline Average & & & & & & 0.49 & -0.28 \\
\hline
\end{tabular}


Table 4. Quality attribute and satisfaction coefficient of general users

\begin{tabular}{|c|c|c|c|c|c|c|c|}
\hline IGB design strategies & A & $\mathrm{O}$ & M & I & $\begin{array}{l}\text { Quality } \\
\text { attribute }\end{array}$ & $\mathrm{SC}$ & DSC \\
\hline \multirow[t]{2}{*}{ B1 Intell. vegetal wall sys. } & 12 & 5 & 1 & 10 & $\mathrm{~A}$ & 0.61 & -0.21 \\
\hline & $43 \%$ & $18 \%$ & $4 \%$ & $36 \%$ & & & \\
\hline \multirow[t]{2}{*}{ B2 Intell. roof greening sys. } & 9 & 6 & 1 & 12 & I & 0.54 & -0.25 \\
\hline & $32 \%$ & $21 \%$ & $4 \%$ & $43 \%$ & & & \\
\hline \multirow[t]{2}{*}{ C1 ICT-based permeable pavement } & 9 & 5 & 2 & 12 & I & 0.50 & -0.25 \\
\hline & $32 \%$ & $18 \%$ & $7 \%$ & $43 \%$ & & & \\
\hline \multirow[t]{2}{*}{ C2 Rainwater infiltration tech. } & 9 & 4 & 2 & 13 & I & 0.46 & -0.21 \\
\hline & $32 \%$ & $14 \%$ & $7 \%$ & $46 \%$ & & & \\
\hline \multirow[t]{2}{*}{ D1 Intell. energy monitoring sys. } & 9 & 4 & 2 & 13 & I & 0.46 & -0.21 \\
\hline & $32 \%$ & $14 \%$ & $7 \%$ & $46 \%$ & & & \\
\hline \multirow[t]{2}{*}{ D2 Inductive shutter } & 16 & 3 & 2 & 7 & $\mathrm{~A}$ & 0.68 & -0.18 \\
\hline & $57 \%$ & $11 \%$ & $7 \%$ & $25 \%$ & & & \\
\hline \multirow[t]{2}{*}{ D3 Solar photoelectric glass } & 12 & 3 & 3 & 10 & $\mathrm{~A}$ & 0.54 & -0.21 \\
\hline & $43 \%$ & $11 \%$ & $11 \%$ & $36 \%$ & & & \\
\hline \multirow[t]{2}{*}{ D4 Nano-coating solar panels } & 11 & 1 & 2 & 14 & I & 0.43 & -0.11 \\
\hline & $39 \%$ & $4 \%$ & $7 \%$ & $50 \%$ & & & \\
\hline \multirow[t]{2}{*}{ D5 Inductive ventilating tower } & 8 & 4 & 3 & 13 & I & 0.43 & -0.25 \\
\hline & $29 \%$ & $14 \%$ & $11 \%$ & $46 \%$ & & & \\
\hline \multirow[t]{2}{*}{ D6 Earth cooling tube sys. } & 7 & 4 & 2 & 15 & I & 0.39 & -0.21 \\
\hline & $25 \%$ & $14 \%$ & $7 \%$ & $54 \%$ & & & \\
\hline \multirow[t]{2}{*}{ D7 Intell. VRV sys. } & 6 & 4 & 5 & 13 & I & 0.36 & -0.32 \\
\hline & $21 \%$ & $14 \%$ & $18 \%$ & $46 \%$ & & & \\
\hline \multirow[t]{2}{*}{ D8 Intell. heat exchanger sys. } & 8 & 6 & 3 & 11 & I & 0.50 & -0.32 \\
\hline & $29 \%$ & $21 \%$ & $11 \%$ & $39 \%$ & & & \\
\hline \multirow[t]{2}{*}{ D9 Intell. cold storage sys. } & 9 & 5 & 2 & 12 & I & 0.50 & -0.25 \\
\hline & $32 \%$ & $18 \%$ & $7 \%$ & $43 \%$ & & & \\
\hline \multirow[t]{2}{*}{ D10 Solar-tracking light-guide plates } & 14 & 4 & 5 & 5 & $\mathrm{~A}$ & 0.64 & -0.32 \\
\hline & $50 \%$ & $14 \%$ & $18 \%$ & $18 \%$ & & & \\
\hline \multirow[t]{2}{*}{ D11 Smart roof light-guide sys. } & 11 & 4 & 5 & 8 & $\mathrm{~A}$ & 0.54 & -0.32 \\
\hline & $39 \%$ & $14 \%$ & $18 \%$ & $29 \%$ & & & \\
\hline \multirow[t]{2}{*}{ E1 Intell. CO2 monitoring sys. } & 5 & 7 & 3 & 13 & I & 0.43 & -0.36 \\
\hline & $18 \%$ & $25 \%$ & $11 \%$ & $46 \%$ & & & \\
\hline \multirow[t]{2}{*}{ F1 BIM-based management sys. } & 8 & 2 & 3 & 15 & I & 0.36 & -0.18 \\
\hline & $29 \%$ & $7 \%$ & $11 \%$ & $54 \%$ & & & \\
\hline F2 RFID-based material checking & 8 & 5 & 2 & 13 & $\mathrm{I}$ & 0.46 & -0.25 \\
\hline & $29 \%$ & $18 \%$ & $7 \%$ & $46 \%$ & & & \\
\hline G1 IEQ monitoring sys. & 3 & 10 & 7 & 8 & $\mathrm{O}$ & 0.46 & -0.61 \\
\hline & $11 \%$ & $36 \%$ & $25 \%$ & $29 \%$ & & & \\
\hline G2 Auto. humidity controlling sys. & 5 & 13 & 6 & 4 & $\mathrm{O}$ & 0.64 & -0.68 \\
\hline & $18 \%$ & $46 \%$ & $21 \%$ & $14 \%$ & & & \\
\hline G3 Adaptive lighting sys. & 11 & 7 & 5 & 5 & $\mathrm{~A}$ & 0.64 & -0.43 \\
\hline & $39 \%$ & $25 \%$ & $18 \%$ & $18 \%$ & & & \\
\hline G4 Intell. fire alert sys. & 3 & 5 & 15 & 5 & M & 0.29 & -0.71 \\
\hline & $11 \%$ & $18 \%$ & $54 \%$ & $18 \%$ & & & \\
\hline G5 Intell. fire compartment sys. & 6 & 5 & 11 & 6 & $\mathrm{M}$ & 0.39 & -0.57 \\
\hline & $21 \%$ & $18 \%$ & $39 \%$ & $21 \%$ & & & \\
\hline G6 Build damage monitoring sys. & 7 & 5 & 9 & 7 & $\mathrm{M}$ & 0.43 & -0.50 \\
\hline & $25 \%$ & $18 \%$ & $32 \%$ & $25 \%$ & & & \\
\hline H1 Intell. graywater recycling sys. & 11 & 4 & 8 & 5 & A & 0.54 & -0.43 \\
\hline & $39 \%$ & $14 \%$ & $29 \%$ & $18 \%$ & & & \\
\hline H2 Inductive rainwater recycling sys. & 2 & 12 & 5 & 9 & $\mathrm{O}$ & 0.50 & -0.61 \\
\hline & $7 \%$ & $43 \%$ & $18 \%$ & $32 \%$ & & & \\
\hline H3 Inductive water-saving equip. & 7 & 10 & 5 & 6 & $\mathrm{O}$ & 0.61 & -0.54 \\
\hline & $25 \%$ & $36 \%$ & $18 \%$ & $21 \%$ & & & \\
\hline Average & & & & & & 0.49 & -0.35 \\
\hline
\end{tabular}


Table 5. Similarities and differences of respondents' opinions

\begin{tabular}{lll}
\hline & Professional designers & General users \\
\hline $\mathrm{A}$ & - External environments \& Building components & - External environments \& Building components \\
& (B1, D2, D3, D10, D11, H1) & (B1, D2, D3, D10, D11, H1) \\
& - Energy-saving (D5, D6) & - Indoor environment (G3) \\
& - Indoor environment (G1) & - Indoor environment (G1, G2) \\
$\mathrm{O}$ & & - Water-saving (H2, H3) \\
& & - Advanced ICT technologies (C2, D4, D9, E1, F1, F2) \\
I & - Advanced ICT technologies (C2, D4, D9, E1, F1, F2) & - Energy-saving (D1, D5, D6, D7, D8) \\
& - Indoor environment (G2, G3) & \\
& - Water-saving (H2, H3) & - Human safety (G4, G5, G6) \\
M & - Human safety (G4, G5, G6); & \\
& - Energy-saving (D1, D7, D8) &
\end{tabular}

The result implies that there is still much room for improving energy awareness and environmental consciousness education for users.

The second cluster of discrepant opinions between these two groups appears to be the strategies of indoor environment issues, such as "G1 IEQ monitoring system”, "G2 Automatic humidity controlling system", and "G3 Adaptive lighting system". Unlike professional designers who usually pay more attention to daily energy-saving issues, general users, on the contrary, are more sensitive to these indoor environment quality problems. These strategies acquired from general users are classified into "Attractive" or "One-dimensional" attributes, showing that customer satisfaction is proportional to the level of fulfillment of these strategies.

A similar situation also occurs over the last two strategies: "H2 Inductive rainwater recycling system" and "H3 Inductive water-saving equipment". These two strategies seem to be the basic design requirements for general users ("One-dimensional" attribute), whereas professional designers hold a negative attitude ("Indifferent" attribute). The reason might be that professional designers have taken these strategies for granted and easily overlooked the basic requirements for users.

\subsection{Customer satisfaction matrix}

On the basis of the concept of CSC, a customer satisfaction matrix can be developed to quantitatively reflect the priority of adopting these IGB design strategies. This matrix, depicted in Fig. 3, is composed of four quadrants divided by an $X$-axis, representing the level of satisfaction, and a $Y$-axis, representing the level of dissatisfaction. The origin of this matrix is the average of SC and DSC. Strategies located in the quadrant I, therefore, imply that these strategies have greater impacts on highly increasing customer's satisfaction and dissatisfaction and should be implemented first.
Strategies in the quadrant III, on the contrary, could be suspended due to their low influence on customer's satisfaction and dissatisfaction. Considering the efficiency of budget utilization, decision makers can decide whether they would like to invest in strategies located in quadrants II and IV since these strategies can only improve either customer's satisfaction or dissatisfaction and do not have much effect on the result.

Fig. 3 also reveals insightful information for both professional designers and general users. For
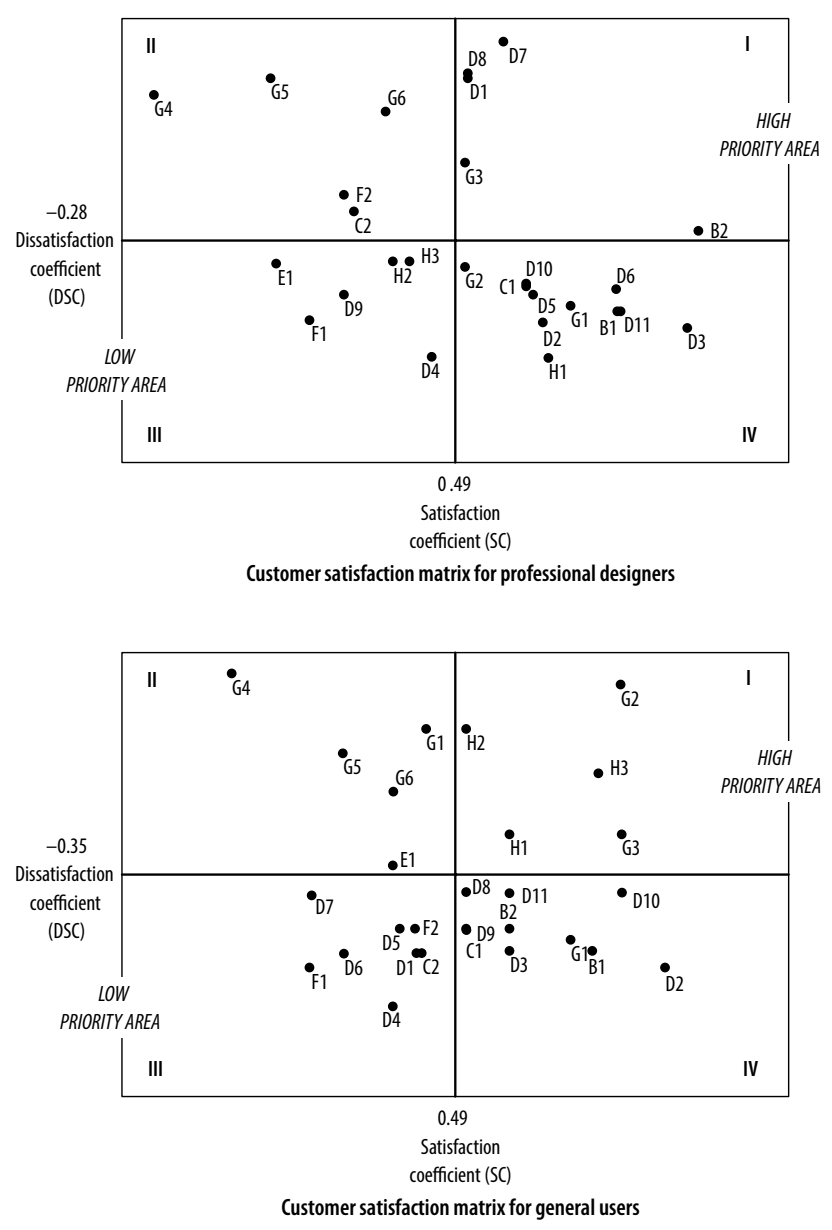

Fig. 3. Customer satisfaction matrix 
example, designers prefer the strategies of "D1 Intelligent energy monitoring system" and "D7 Intelligent VRV system", whereas users regard them as unimportant strategies. Similarly, the strategies such as "H2 Inductive rainwater recycling system" and "H3 Inductive water-saving equipment" are critical to users but insignificant to designers. These two groups have the same preferences to some strategies such as "G3 Adaptive lighting system" for a prior execution and "F1 BIM-based management system" and "D4 Nano-coating solar panels" for a stay of implementation. The matrix is a useful tool for design communication to discover the real requirements and expectations, providing a good opportunity to reexamine and decrease this gap between the designers and users.

\section{DISCUSSIONS}

This research applies a Kano quality model to understand customer's (general users and professional designers) satisfaction, preferences, and acceptability toward IGB design strategies. From the preceding data analysis and the three distinct research questions proposed, several findings are further discussed and elaborated next.

First, it is observed that customers' awareness and understanding of IGB design strategies actually reflect their attitudes and preferences for adopting these strategies. For some innovative and advanced technologies, such as "D4 Nano-coating solar panels", "D9 Intelligent cold storage system", "F1 BIM-based management system", and "F2 RFID-based material checking", which are not easily perceived by customers, they express their indifference regardless of how these strategies can bring benefits and advantages to the building. IGB is still a relatively new and interdisciplinary field, and apparently it requires more time to promote the development and applications in the industries. For professional designers, the lack of experience, knowledge, and standards on the implementation of IGB projects lead them to be more conservative when adopting these design strategies. This inference is similar to the previous study regarding the implementation experience of green buildings (Tam et al. 2012). For general users, lack of education and awareness might be the important obstacle to the acceptability of the IGB market, and similar results are also supported by other studies for exploring the obstacles promoting green buildings (Chan et al. 2009; Ofori, Ho 2004).

Second, customers intend to be satisfied with some IGB design strategies related to basic ICT- based building component and environment issues, classified as "Attractive" attributes, and dissatisfied with strategies related to human safety issues, classified as "Must-be" attributes, once these strategies are not fulfilled. The explanation for the findings is rational since human safety is the most important requirement for customers, and once this safety issues are threatened, they will be very dissatisfied. It is consistent with some studies revealing that minimizing the risk of physical injury and the death of occupants by providing effective evacuation and monitoring systems is key to safe living (Ho et al. 2008; Kobes et al. 2010). Unlike these "Must-be" attributes, "Attractive" attributes, at some degree, are like "icing on the cake" to customers. Even without adopting these ICT-based technologies, occupants can still lead a normal life or find other alternative solutions to fulfill their living requirements.

Third, it is surprising to find that there are indeed gaps between designers and users in the perceptions of some IGB design strategies. Users are not concerned about energy-saving issues, whereas designers give priority to these strategies. On the contrary, users pay more attention to water resource and indoor environment issues, while designers hold indifferent attitudes toward these strategies. These findings reveal three perspectives that are crucial to the successful promotion of the IGB market: (1) Both designers and users need more environmental consciousness education to build an environment-friendly society; (2) A continuous communication mechanism for both sides to balance the requirements and decrease the design gap is urgently required; (3) The government interventions in economic, political, educational, and environment issues are essential to reduce the resistance and to arouse interests in the IGB market. The assumption can be supported by findings of some empirical studies for spurring the green building market (Chan et al. 2009; Ofori, Ho 2004; Tam et al. 2012).

On the basis of the result depicted in Fig. 3, there is certainly room for improvements in the application of this customer satisfaction matrix. For example, the concept of subjective probability can be adopted to calculate the expected value of customer's SC and DSC, which can extract customer's expectations and preferences more accurately. In addition, the decision makers can further establish a priority list of these IGB design strategies and then develop a systematic approach to optimize the strategies considering the trade- 
off between costs and customer satisfaction. With this approach, the system will be qualitatively and quantitatively comprehensive and can compensate the insufficiency of the Kano model that focuses more on qualitative assessment of quality attributes (Xu et al. 2009).

\section{CONCLUSIONS}

Embodying ICT components, intelligent materials, products, and technologies into green buildings to develop the concept of Intelligent Green Buildings (IGBs) has prompted a revolution in the building industry. In view of the benefits of transforming from traditional buildings into IGBs, many global organizations including those in Taiwan are making efforts to create better living environments, which are both sustainable and intelligent. However, the assessment for ICT-green technologies and strategies, namely IGB design strategies, is still in a preliminary stage and all participants in the related industries are unsure as to how to find the right path to implement these technologies and strategies.

This study attempts to apply a Kano two-dimensional quality model to classify possible IGB design strategies and adopt the customer satisfaction coefficient to quantitatively evaluate professional designers' and general users' satisfaction and preferences toward these strategies. This is the first step toward successful implementation of these strategies by learning about market demands and customer's acceptability. The experimental result further proves that the proposed approach could be a useful tool to explore similarities and discrepancies of strategy preferences between designers and users, and accordingly to support design communication for decreasing the gap between these two sides.

Lessons with respect to IGB issues learned from investigating experiences in Taiwan might be also extended to other organizations facing similar research requirements and problems. Limited by the investigation areas and available projects, continuous updates of these IGB design strategies are necessary. This iterative process is essential to the successful promotion of the IGB market. For further research, it will be also desirable to develop an efficient decision support tool for decision makers to optimize the strategies, considering the trade-off between strategies costs and customer satisfaction.

\section{ACKNOWLEDGMENTS}

The authors appreciate the valuable comments from editors and anonymous reviewers. Their detailed comments helped to improve the clarity and focus of this study. The authors are also grateful for the funding from the National Science Council of Taiwan (R.O.C.) under the Project No. NSC 101-2627-E-011-001-MY3 to support the continuation of this study and the dissemination of these results.

\section{REFERENCES}

ABRI. 2003. Taiwan evaluation manual for green building in Taiwan (English Edition). Architecture and Building Research Institute (ABRI), Ministry of the Interior.

ABRI. 2011. Evaluation manual for intelligent building (2011 version) (Chinese Edition). Architecture and Building Research Institute (ABRI), Ministry of the Interior, Evaluation Manual for Intelligent Building (2011 version) (Chinese Edition).

Adeli, H. 2008. Smart structures and building automation in the $21^{\text {st }}$ century, in The $25^{\text {th }}$ International Symposium on Automation and Robotics in Construction, Vilnius, Lithuania, June 26-29, 2008, 5-10.

Berger, C.; Blauth, R.; Boger, D.; Bolster, C.; Burchill, G.; Duouchel, W.; Pouliot, F.; Richter, R.; Rubinoff, A.; Shen, D.; Timko, M.; Walden, D. 1993. Kano's methods for understanding customer-defined quality, Center for Quality Management Journal 2(4): 3-35.

Boyle, C. A. 2005. Sustainable buildings, in Proceedings of the Institution of Civil Engineers Engineering Sustainability 158: 41-48.

BRE Global. 2008. BREEAM offices 2008 assessor manual. Available at: http://www.breeam.org/page. jsp?id=109.

Chan, E. H. W.; Qian, Q. K.; Lam, P. T. I. 2009. The market for green building in developed Asian cities the perspectives of building designers, Energy Policy 37(8): 3061-3070.

http://dx.doi.org/10.1016/j.enpol.2009.03.057

Chau, C. K.; Tse, M. S.; Chung, K. Y. 2010. A choice experiment to estimate the effect of green experience on preferences and willingness-to-pay for green building attributes, Building and Environment 45(11): 2553-2561. http://dx.doi.org/10.1016/j.buildenv.2010.05.017

Chen, S. H. 2002. Global production networks and information technology: the case of Taiwan, Industry and Innovation 9(3): 249-265. http://dx.doi.org/10.1080/1366271022000034480

Clements-Croome, T. D. J. 1997. What do we mean by intelligent buildings?, Automation in Construction 6(5-6): 395-400.

http://dx.doi.org/10.1016/S0926-5805(97)00018-6 
Executive Yuan. 2010. Intelligent green building promotion program (in Chinese). Available at: http://www.ey.gov. tw/Upload/RelFile/88/76048/0121717101571.pdf

GBC Green Building Tool. 2005. International Initiative for a Sustainable Built Environment, iiSBE. Available at: http://iisbe.org/gbc2k/gbc-start.htm

Ho, M. C. 2011. Green building promotion: current development and future perspectives in Taiwan. Available at: http://unfccc.saveoursky.org.tw/2011cef/images/ cadiis/presentation/s1t1.pdf

Ho, D. C. W.; Chau, K. W.; Cheung, A. K. C.; Yau, Y.; Wong, S. K.; Leung, H. F.; Lau, S. S. Y.; Wong, W. S. 2008. A survey of the health and safety conditions of apartment buildings in Hong Kong, Building and Environment 43(5): 764-775. http://dx.doi.org/10.1016/j.buildenv.2007.01.035

Kano, N.; Seraku, N.; Takahashi, F.; Tsuji S. 1984. Attractive quality and must-be quality, Journal of the Japanese Society for Quality Control 14(2): 39-48.

Kobes, M.; Helsloot, I.; de Vries, B.; Post, J. G. 2010. Building safety and human behaviour in fire: a literature review, Fire Safety Journal 45(1): 1-11. http://dx.doi.org/10.1016/j.firesaf.2009.08.005

Lin, S. P.; Yang, C. L.; Chan, Y. H.; Sheu, C. 2010. Refining Kano's quality attributes-satisfaction' model: a moderated regression approach, International Journal of Production Economics 126(2): 255-263. http://dx.doi.org/10.1016/j.ijpe.2010.03.015

Matzler, K.; Hinterhuber, H. H. 1998. How to make product development projects more successful by integrating Kano's model of customer satisfaction into quality function deployment, Technovation 8(1): 2538. http://dx.doi.org/10.1016/S0166-4972(97)00072-2

Mickaitytè, A.; Zavadskas, E. K.; Kaklauskas, A.; Tupènaitè, L. 2008. The concept model of sustainable buildings refurbishment, International Journal of Strategic Property Management 12(1): 53-68. http://dx.doi.org/10.3846/1648-715X.2008.12.53-68

Nunnally, J. C. 1978. Psychometric theory. New York: McGraw-Hill.

Ofori, G.; Ho, L. K. 2004. Translating Singapore architects' environmental awareness into decision making, Building Research and Information 32(1): 27-37. http://dx.doi.org/10.1080/09613210210132928

Pérez-Lombard, L.; Ortiz, J.; Pout, C. 2008. A review on buildings energy consumption information, Energy and Buildings 40(3): 394-398.

http://dx.doi.org/10.1016/j.enbuild.2007.03.007
Raju, P.; Ahmed, V. 2012. Enabling technologies for developing next-generation learning object repository for construction, Automation in Construction 22: 247257. http://dx.doi.org/10.1016/j.autcon.2011.07.008

Sinopoli, J. 2008. How do smart buildings make a building green?, The Magazine of the Continental Automated Buildings Association 5(1): 11-13.

Skibniewski, M. J. 2008. Optimal buildings through automation technology: toward systems unification for secure, intelligent, green, and immune buildings, in The $25^{\text {th }}$ International Symposium on Automation and Robotics in Construction, June 26-29, 2008, Vilnius, Lithuania, 1-4.

Tam, V. W. Y.; Hao, J. L.; Zeng, S. X. 2012. What affects implementation of green buildings? An empirical study in Hong Kong, International Journal of Strategic Property Management 16(2): 115-125. http://dx.doi.org/10.3846/1648715X.2011.645559

USGBC. 1999. LEED-Leadership in energy and environmental design: green building rating system, US Green Building Council (USGBC). Available at: http:// www.usgbc.org/DisplayPage.aspx?CMSPageID=222

Wassenaar, H. J.; Cheng, J.; Sudjianto, A.; Chen, W. 2005. Enhancing discrete choice demand modeling for decision-based design, Journal of Mechanical Design 127(4): 514-523. http://dx.doi.org/10.1115/1.1897408

Wigginton, M.; Harris, J. 2002. Intelligent skin. Oxford: Architectural Press.

Wong, J. K. W.; Li, H.; Wang, S.W. 2005. Intelligent building research: a review, Automation in Construction 14(1): 143-159. http://dx.doi.org/10.1016/j.autcon.2004.06.001

Xu, Q.; Jiao, R. J.; Yang, X.; Helander, M.; Khalid, H. M.; Opperud, A. 2009. An analytical Kano model for customer need analysis, Design Studies 30(1): 87-110. http://dx.doi.org/10.1016/j.destud.2008.07.001

Xue, X.; Shen, Q.; Fan, H.; Li, H.; Fan, S. 2012. IT supported collaborative work in $\mathrm{A} / \mathrm{E} / \mathrm{C}$ projects: a tenyear review, Automation in Construction 21: 1-9. http://dx.doi.org/10.1016/j.autcon.2011.05.016

Yang, L. R.; Chen, J. H.; Wang, H. W. 2012. Assessing impacts of information technology on project success through knowledge management practice, Automation in Construction 22: 182-191. http://dx.doi.org/10.1016/j.autcon.2011.06.016 


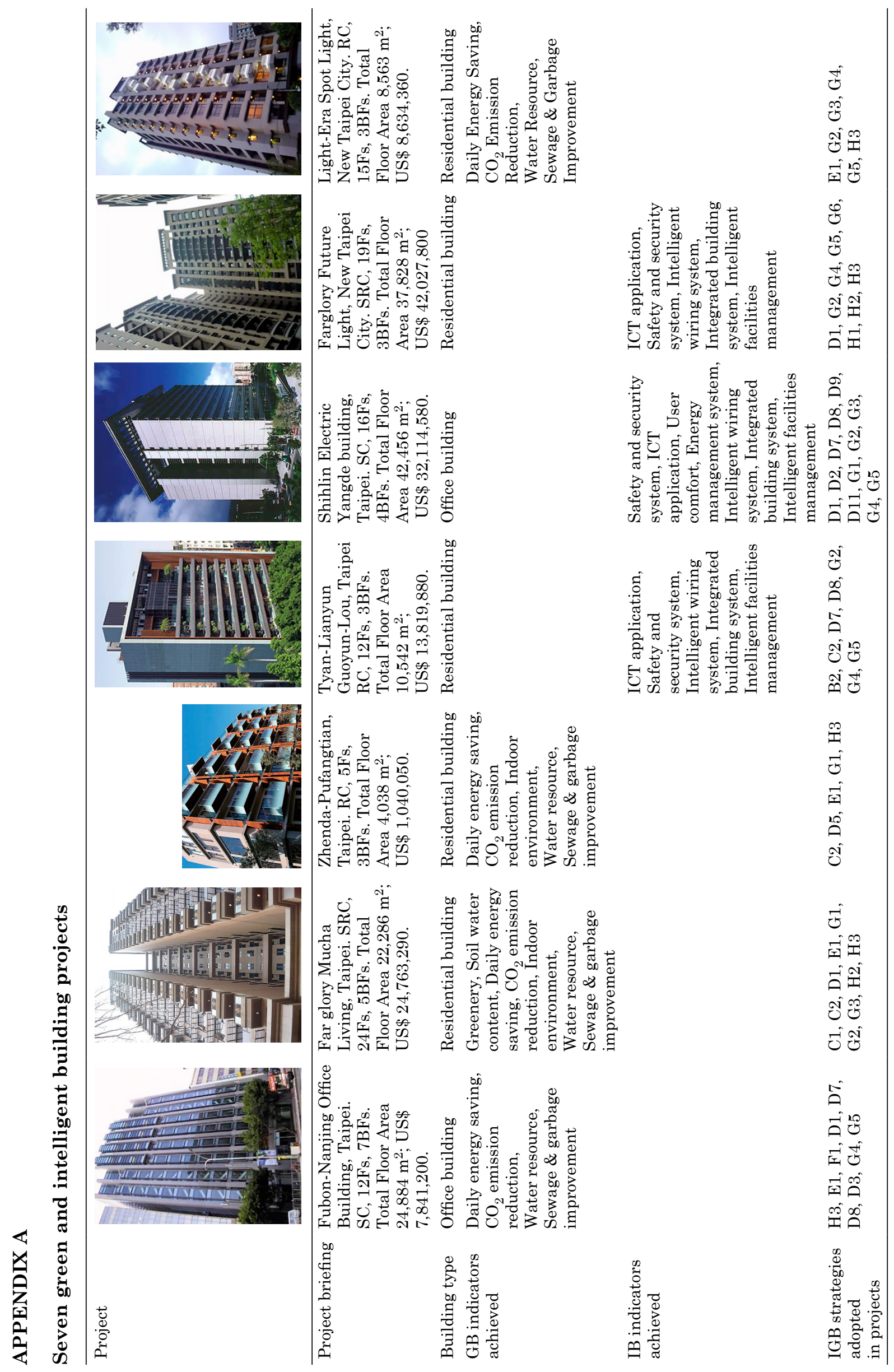




\section{APPENDIX B}

\section{Profiles of respondents}

All of the 30 professional designers included in the study are experienced and activate in the Taiwan architecture market. During the course of the investigation, 5 of them are principal architects of the firms, 7 of them are project managers, 13 of them are design directors, and 5 of them are senior architectural designers. Office, housing, and public building projects have been their major professional work during the past ten years. The background of the survey respondents showed that the establishment time of their firms averaged 13.2 years (between less than 1 year and 48 years), and the firms' capital averaged approximately US\$ 100,000 (between US $\$ 30,000$ and US $\$ 6,600,000$ ). The analyzed data were acquired from a survey of the designers at the annual member meeting of Taiwan Architects Association (TAA) in 2012.

The invited users are occupants of high-rise office buildings and public housing buildings in Taipei City. They are both the end-users and superiors of their occupied communities or buildings. For example, 18 of them are directors from different communities committee and the occupancy time of their positions averaged 10.4 years. In addition, 12 of them are facility managers of office buildings and the average service period is about 8.2 years. Through a conference on agendas of Intelligent and Sustainable Refurbishment co-hosted by the Taipei City government and a specific construction company, these users were invited to fill out the questionnaire. It provided an opportunity to objectively gather information and expectation from these users. 